\title{
Asleep blood pressure: relevance to the proper definition of isolated-office and masked hypertension
}

\author{
Hypertension Research (2013) 36, 471-472; doi:10.1038/hr.2012.225; published online 24 January 2013
}

A recently published study by Nasothimiou et al. ${ }^{1}$ concluded that daytime at-home blood pressure (BP) self-measurement is a reliable alternative to ambulatory $\mathrm{BP}$ monitoring (ABPM) to identify isolated-office, masked, and sustained hypertension. Current guidelines $^{2}$ define normotension as a consistently normal BP and 'sustained' hypertension as consistently elevated clinic and ambulatory BP measurements. Discrepancies between clinic and ABPM-derived values have been defined as 'isolated-office' hypertension, that is, elevated clinic BP but normal ambulatory BP, and 'masked' hypertension, that is, normal clinic BP but elevated ambulatory BP. ${ }^{2}$ These guidelines also recommend the diagnosis of hypertension be based on abnormally elevated ABPMdetermined awake and/or asleep BP means, using separate specified threshold values. ${ }^{2}$ However, past studies, including that of Nasothimiou et al., ${ }^{1}$ categorized individuals, as erroneously suggested in the guidelines themselves, as isolated-office hypertension or masked hypertension based solely on a comparison of clinic and awake-time BP values, whether the latter were derived from at-home self-assessments ${ }^{1}$ or $\mathrm{ABPM}{ }^{3}$ and disregarding entirely the asleep BP mean, which is also recommended by the guidelines for defining hypertension.

A major limitation of all these studies ${ }^{1,3}$ is the process by which patients are classified; a comparison of clinic and at-home or ABPM-derived awake or even 24-h BP means would include, in each of the four resulting categories, individuals with either normal or elevated asleep BP means and, thus, those with markedly different cardiovascular disease (CVD) risk. ${ }^{4}$ The literature indicates that the asleep BP mean better predicts CVD risk than the awake or 24-h BP means, ${ }^{4}$ and that the progressive reduction of the asleep BP during follow-up in outcome trials is the strongest predictor of decreased CVD risk, in both people with normal and elevated BP at baseline. ${ }^{4}$ Particularly relevant are the recent findings of the Monitorización Ambulatoria para Predicción de Eventos Cardiovasculares (MAPEC) Study. They show that the progressive decrease during follow-up in the asleep BP mean is better achieved when the entire daily dose of one or more hypertension medications is ingested at bedtime rather than in the morning, the most typical time of treatment. ${ }^{5-7}$

The MAPEC Study was designed to investigate whether a bedtime vs. conventional morning-time hypertension therapy regimen exerts different changes in the 24-h BP profile and reduces CVD risk. ${ }^{4-7}$ A total of 3344 subjects with baseline BP ranging from normotension to sustained hypertension according to ABPM criteria were prospectively studied throughout a 5.6-year median follow-up. Hypertensive participants were randomized to ingest all their prescribed hypertension medications upon awakening or the entire daily dose of one or more of them at bedtime. At baseline and thereafter annually (or more frequently if hypertension treatment was adjusted), ambulatory BP and physical activity (wrist actigraphy) were simultaneously monitored for $48 \mathrm{~h}$ to accurately derive the awake and asleep BP means, thus allowing prospective examination of the role of asleep BP level on the definition of ambulatory hypertension and the associated prognostic value of isolated-office and masked hypertension. ${ }^{8}$

MAPEC Study participants were first divided into categories of normal BP, isolated-office hypertension, masked hypertension and sustained hypertension by comparing their clinic BP and awake BP mean values-as customary in previous studies ${ }^{3}$ - utilizing the recommended thresholds of $140 / 90 \mathrm{~mm} \mathrm{Hg}$ for clinic systolic (SBP)/diastolic BP (DBP) and 135/ $85 \mathrm{~mm} \mathrm{Hg}$ for ABPM-derived awake SBP/ DBP means. ${ }^{2}$ The subjects comprising these four categories were further divided into two additional classes according to whether they had a normal or elevated asleep SBP/DBP mean, utilizing the recommended thresholds of $120 / 70 \mathrm{~mm} \mathrm{Hg}^{2}$ The hazard ratio (HR) of each group-adjusted according to the confounding variables of patient sex and age, diagnosis of diabetes or chronic kidney disease, sleep duration and hypertension treatment time (all medications upon awakening vs. one or more medications at bedtime)was obtained through a Cox regression analysis using subjects with normal clinic SBP/DBP and normal awake and asleep SBP/DBP as reference.

A. Subjects with a normal asleep BP mean had an adjusted HR comparable to those of the normotensive reference group, regardless of their classification according to the awake BP mean; isolated-office ( $\mathrm{HR}=0.87,95 \% \mathrm{CI}$ (0.59-1.29); $P=0.501)$ or masked hypertension (0.71 (0.17-2.91); $P=0.629$; Figure 1). B. Subjects with an elevated asleep BP mean had a significantly higher adjusted HR than those of the normotensive reference group, regardless of their classification according to the awake BP mean; isolatedoffice $(\mathrm{HR}=2.08(1.33-3.24) ; P<0.001)$ or masked hypertension (1.77 (1.03-3.05); $P=0.039$; Figure 1).

C. Subjects from the groups that were labeled either isolated-office or masked hypertension, according to the awake BP mean only, with a normal asleep BP mean had a significantly lower HR of CVD events than those with an elevated asleep BP mean $(P<0.001$; Figure 1$)$.

Apart from the marked difference in CVD risk assessment when subject classification 


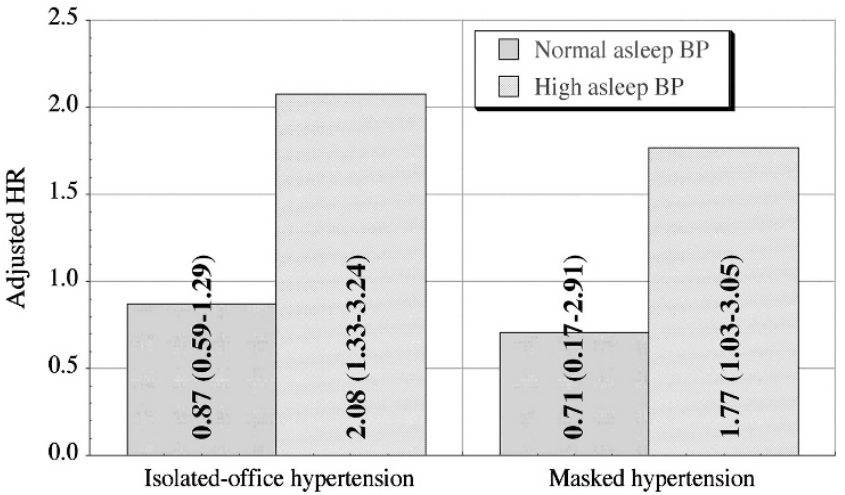

Figure 1 Adjusted hazard ratio (HR) of total cardiovascular disease events in the MAPEC Study. Adjustments were applied according to patient sex and age, diagnosis of type 2 diabetes or chronic kidney disease, sleep duration and hypertension treatment time (all medications upon awakening vs. one or more medications at bedtime). Subjects were classified into the categories of isolated-office hypertension and masked hypertension by comparing the clinic blood pressure (BP) with the ambulatory $\mathrm{BP}$ monitoring (ABPM)-derived awake BP mean and then further divided according to the value of asleep BP mean. Clinic SBP/DBP measurements were considered normal if $<140 / 90 \mathrm{~mm} \mathrm{Hg}$ and were considered elevated otherwise. The ABPM-derived awake SBP/DBP means were considered normal if $<135 / 85 \mathrm{~mm} \mathrm{Hg}$ and were considered elevated otherwise. The ABPM-derived asleep SBP/ DBP means were considered normal if $<120 / 70 \mathrm{~mm} \mathrm{Hg}$ and were considered elevated otherwise. A full color version of this figure is available at the Hypertension Research journal online.

disregards the asleep BP mean, the MAPEC Study $^{8}$ indicates that the past reported prevalence of the four considered patient categories, that is, normal BP, isolatedoffice, masked and sustained hypertension, is incorrect and, thus, misrepresentative of the actual clinical dimension of isolatedoffice and masked hypertension. Specifically: (i) $58.2 \%$ of subjects with normal office and ambulatory awake BP, who should have been labeled with masked hypertension based on an elevated asleep BP, were in the past labeled as normotensive and, thus, mistakenly included in the reference group to calculate the comparative CVD risk of the other categories; (ii) $38.2 \%$ of subjects with normal office and elevated ambulatory awake BP, but normal asleep BP-which is indicative of low CVD risk-were labeled with masked hypertension; and (iii) $26.3 \%$ of subjects with sustained hypertension-that is, elevated office BP, normal ambulatory awake BP, and elevated asleep BP-have consistently been labeled with isolated-office hypertension. Other reports also found attenuation by about $50 \%$ of the real prevalence of isolated-office hypertension and a significant two-fold increase in the real prevalence of masked hypertension, mainly in high-risk cohorts involving a preponderance of elderly, type 2 diabetic, chronic kidney disease, and resistant hypertension patients, who are prone to having an elevated asleep BP mean and a 24-h non-dipper/riser BP pattern. ${ }^{9,10}$

In conclusion, the asleep BP mean, determined by ABPM, must be used to properly identify out-of-office hypertension and cannot be omitted in the definition of isolatedoffice and masked hypertension. Accordingly, these two conditions cannot be defined by comparing clinic BP with awake-time selfmeasurements at home, as is frequently done $^{3}$ and misleadingly recommended as an alternative to ABPM. ${ }^{1}$

\section{CONFLICT OF INTEREST}

The authors declare no conflict of interest.

\section{ACKNOWLEDGEMENTS}

Research supported by unrestricted grants from Ministerio de Ciencia e Innovación (SAF20097028-FEDER); Consellería de Economía e Industria, Xunta de Galicia (INCITE09-E2R322099ES; IN845B-2010/114; 09CSA018322PR); European Research Development Fund and Consellería de Cultura, Educación e Ordenación Universitaria, Xunta de Galicia (CN2012/251 and CN2012/260); and Vicerrectorado de Investigación, University of Vigo.
Ramón C Hermida ${ }^{1}$, Diana E Ayala ${ }^{1}$, Michael H Smolensky ${ }^{2}$, Artemio Mojón ${ }^{1}$, José R Fernández ${ }^{1}$ and Francesco Portaluppi ${ }^{3,4}$

${ }^{1}$ Bioengineering and Chronobiology Laboratories, University of Vigo, Campus Universitario, Vigo, Spain; ${ }^{2}$ Department of Biomedical Engineering, Cockrell School of Engineering, The University of Texas at Austin, Austin, TX, USA; ${ }^{3}$ Hypertension

Center, University Hospital S. Anna, Ferrara, Italy and ${ }^{4}$ Department of Medical Sciences, University of Ferrara, Ferrara, Italy E-mail: rhermida@uvigo.es

1 Nasothimiou EG, Tzamouranis D, Rarra V, Roussias LG, Stergiou GS. Diagnostic accuracy of home vs. ambulatory blood pressure monitoring in untreated and treated hypertension. Hypertens Res 2012; 35: 750-755.

2 Mancia G, De Backer G, Dominiczak A, Cifkova R Fagard R, Germano G, Grassi G, Heagerty AM Kjeldsen SE, Laurent S, Narkiewicz K, Ruilope L, Rynkiewicz A, Schmieder RE, Struijker HAJ, Zanchetti A. 2007 guidelines for the management of arterial hypertension. The Task Force for the Management of Arterial Hypertension of the European Society of Hypertension (ESH) and of the European Society of Cardiology (ESC). J Hypertens 2007; 25: 1105-1187.

3 Pierdomenico SD, Cuccurullo F. Prognostic value of white-coat and masked hypertension diagnosed by ambulatory monitoring in initially untreated subjects: An updated meta-analysis. Am J Hypertens 2011; 24 : 52-58.

4 Hermida RC, Ayala DE, Mojón A, Fernández JR. Decreasing sleep-time blood pressure determined by ambulatory monitoring reduces cardiovascular risk. J Am Coll Cardiol 2011; 58: 1165-1173.

5 Hermida RC, Ayala DE, Mojón A, Fernández JR Influence of circadian time of hypertension treatment on cardiovascular risk: Results of the MAPEC study. Chronobiol Int 2010; 27: 1629-1651.

6 Hermida RC, Ayala DE, Mojón A, Fernández JR. Influence of time of day of blood pressure-lowering treatment on cardiovascular risk in hypertensive patients with type 2 diabetes. Diabetes Care 2011; 34: 1270-1276.

7 Hermida RC, Ayala DE, Mojón A, Fernández JR. Bedtime dosing of antihypertensive medications reduces cardiovascular risk in CKD. J Am Soc Nephrol 2011; 22: 2313-2321.

8 Hermida RC, Ayala DE, Mojón A, Fernández JR. Sleep time blood pressure and the prognostic value of isolated-office and masked hypertension. Am J Hypertens 2012; 25: 297-305.

9 Ayala DE, Moyá A, Crespo JJ, Castiñeira C, Domínguez Sardiña M, Gomara S, Sineiro E, Mojón A, Fontao MJ, Hermida RC on behalf of the Hygia Project Investigators. Circadian pattern of ambulatory blood pressure in hypertensive patients with and without type 2 diabetes. Chronobiol Int (e-pub ahead of print 25 October 2012).

10 Mojón A, Ayala DE, Piñeiro L, Otero A, Crespo JJ, Moyá A, Bóveda J, Pérez de Lis J, Fernández JR, Hermida $\mathrm{RC}$ on behalf of the Hygia Project Investigators. Comparison of ambulatory blood pressure parameters of hypertensive patients with and without chronic kidney disease. Chronobiol Int (e-pub ahead of print 25 October 2012). 